\title{
Formation of Ohmic Contacts to ZnO
}

\author{
Janus, H. M.
}

\section{Published in:}

Review of Scientific Instruments

Link to article, DOI:

$10.1063 / 1.1684710$

Publication date:

1970

Document Version

Publisher's PDF, also known as Version of record

Link back to DTU Orbit

\section{Citation (APA):}

Janus, H. M. (1970). Formation of Ohmic Contacts to ZnO. Review of Scientific Instruments, 41(7), 1099-1100. https://doi.org/10.1063/1.1684710

\section{General rights}

Copyright and moral rights for the publications made accessible in the public portal are retained by the authors and/or other copyright owners and it is a condition of accessing publications that users recognise and abide by the legal requirements associated with these rights.

- Users may download and print one copy of any publication from the public portal for the purpose of private study or research.

- You may not further distribute the material or use it for any profit-making activity or commercial gain

- You may freely distribute the URL identifying the publication in the public portal

If you believe that this document breaches copyright please contact us providing details, and we will remove access to the work immediately and investigate your claim. 
TARLE I. Truth table for counter and logic function outputs.

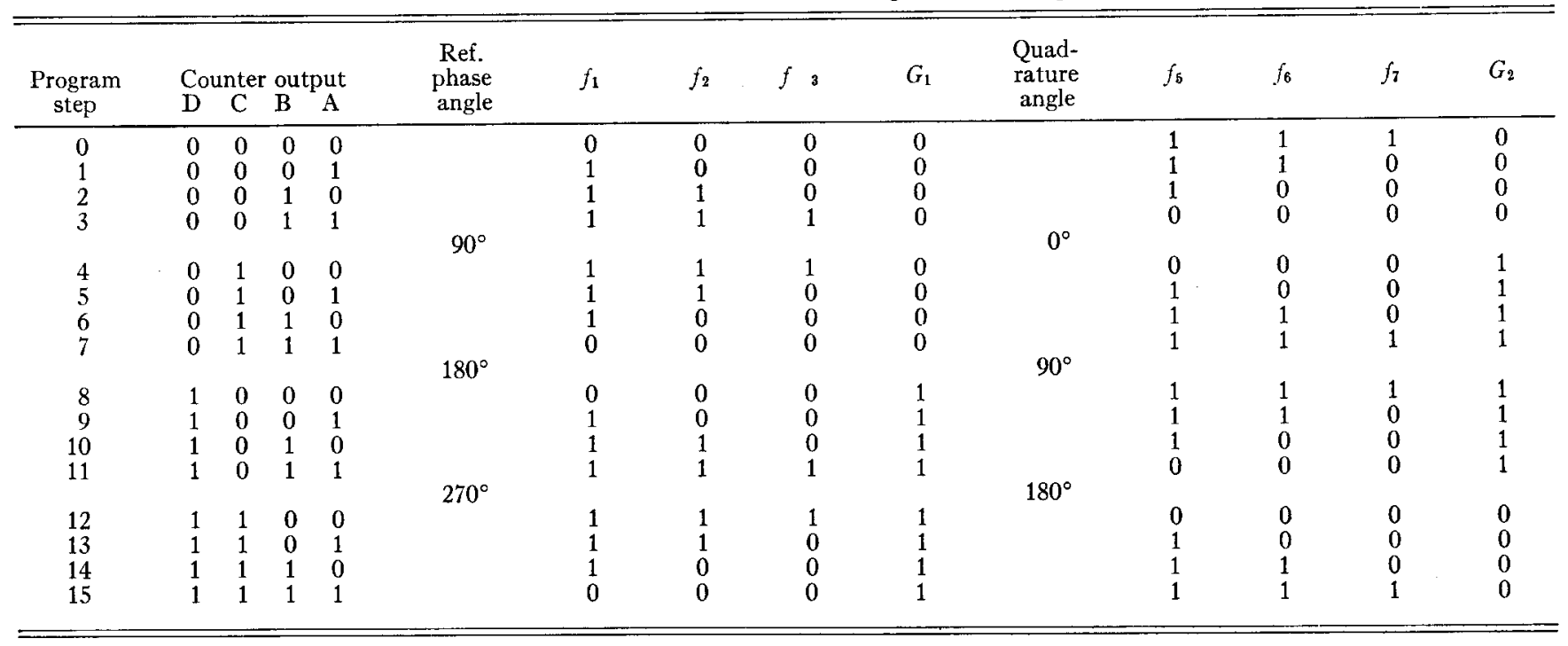

From the technique described above, it should be apparent that generation of in-phase and quadrature components depends only on the nature of the logic functions applied to the summing resistors and FET gates in the two analog processing sections.

Table I shows the relationship between the sine wave generating logic functions and the program steps 0-15 generated by the counter. These program steps are counter outputs A-D in binary. The truth table functions $f_{\mathbf{1}}$ through $f_{3}$, derived by gating the counter outputs, are used in conjunction with $f_{4}$ (logical 1) to generate the reference phase quasisinusoid shown in Fig. 1. Functions $f_{5}-f_{7}$ are used to generate the quadrature quasisinusoid in conjunction with $f_{8}$ (logical 1). Gating functions $G_{1}$ and $G_{2}$ shown in. Table $I$ are used for converting the unipolar waveform shown in Fig. 1 to a bipolar waveform shown in Fig. 2.

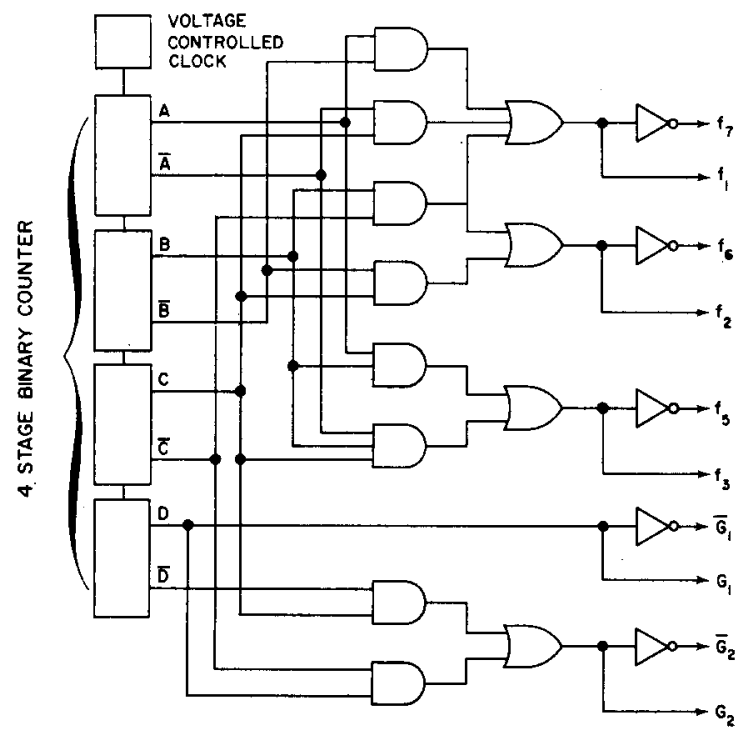

FIG. 3. Logic diagram for generation of the quasisinusoid functions.
Figure 3 shows the logic schematic used to generate these truth table functions.

The logical relationships would not be as simple for polyphase systems, and a three phase system would require a program counter truncated at some multiple of 3 . The clock must run at output frequency times the number of program counter steps, 16 in this case. A wide range voltage controlled multivibrator was used to provide the two decade frequency variation to the four bit counter. This clock input system yields the interesting possibility of automatic motor speed control in response to a transducer system with frequency output.

Advantages of this system are that output phases and amplitudes are absolute and independent of frequency, use of a clock instead of an oscillator permits large frequency excursions without decade ranges, and remote frequency control may be employed. The disadvantage is distortion in the output waveform due to discontinuities. This waveform can be improved, however, by using more program counter steps.

* Work performed at the National Bureau of Standards under the sponsorship of the U. S. Atomic Energy Commission, Contract Agreement AT (49-2)-1165, project 2750476.

${ }^{1} \mathrm{H}$. Sixsmith and P. Giarratano, "A Miniature Centrifugal Pump" (to be published).

\section{Formation of Ohmic Contacts to $\mathrm{ZnO}$}

\author{
H. M. JANUS \\ Physics Department III, The Technical University of Denmark, \\ Lyngby, Denmark
}

(Received 25 February 1970)

$\mathrm{T}$ HE formation of Ohmic contacts to wide bandgap n-type II-VI compound semiconductors is in most cases difficult, ${ }^{1}$ due to the lack of an adequate contact metal, i.e., a metal with a work function smaller than the 
work function (or electron affinity) of the semiconductor. Another difficulty arises for $\mathrm{ZnO}$ in particular because this material adsorbs oxygen ${ }^{2}$ at the surfaces. This gives rise to a potential barrier in addition to the one present at an interface between the semiconductor and the adjacent metal.

In order to overcome the problem of the potential barrier $\phi_{B}$ due to the difference between the work functions, it is necessary to minimize the barrier width $t$. This facilitates electron tunneling through the forbidden region. The tunnel current $^{1}$ is proportional to $\exp \left(-\right.$ const $\left.\cdot \phi_{B} \cdot t\right)$ and $t$ is known to be proportional to $N^{-\frac{1}{2}}$, where $N$ indicates the number of free carriers per unit volume. A highly doped surface layer should thus improve the possibilities for making an Ohmic contact. In the case of low resistivity $\mathrm{ZnO}$, i.e., up to $10 \Omega \cdot \mathrm{cm}$, the problem of contacting has been overcome by simply pressing indium onto the surfaces.

In this note a method is described for making Ohmic contacts to high resistivity $\mathrm{ZnO}$ (greater than $10 \Omega \cdot \mathrm{cm}$ ). Contacts made by evaporating and alloying indium onto the semiconductor turned out to be strongly rectifying in this case. In fact, to the author's knowledge no successful method has previously been described.

The technique involved a combination of desorption of oxygen and indiffusion of zinc. The details of the procedure were as follows.

The $\mathrm{ZnO}$ single crystal was first cleaned in carbon tetrachloride, and, when the surface finish was of minor importance, etched in a mixture of lactic acid and concentrated $\mathrm{HNO}_{3}(10: 1)$. A shot of high purity $\mathrm{Zn}$ was similarly cleaned and etched in $25 \% \mathrm{HNO}_{3}$. The $\mathrm{Zn}$ shot and the $\mathrm{ZnO}$ crystal were placed in an oven at $550^{\circ} \mathrm{C}$ for a period depending on the resistivity of the $\mathrm{ZnO}$, ranging from $5 \mathrm{~min}$ for $10 \Omega \cdot \mathrm{cm}$ material to $\frac{1}{2} \mathrm{~h}$ for $10^{4} \Omega \cdot \mathrm{cm}$ material. After the heating the ampul was cooled rapidly and oxidation of the $\mathrm{Zn}$ was observed. The highly conducting surfaces, where contacts were not wanted, were removed by appropriate masking and etching $(\mathrm{HCl}$ or the above mentioned $\mathrm{ZnO}$ etch). Metallic contact to the surface was ensured either by pressure or by wetting with an indiumgallium eutectic liquid (1:1).

After the process, the surface resistance was measured to be less than $50 \Omega / \mathrm{sq}$ and no nonlinearity (less than $1 \%$ ) in the $I-V$ characteristics of the bulk material was observed until acoustoelectric interaction became important at an electron drift velocity equal to the velocity of sound. The characteristics were symmetrical for reverse biasing and the measured resistances of different samples from one crystal were in agreement with the bulk resistivity.

Copper- and lithium-doped $\mathrm{ZnO}$ of resistivities from 10 to $10^{4} \Omega \cdot \mathrm{cm}$ has been successfully contacted employing this method, and used for an acoustoelectric oscillator, ${ }^{3,4}$ in which it is essential not to have any loss of power in the contacts.
The author is grateful to K. F. Nielsen and M. H. Jørgensen for valuable discussions.

1 B. Schwartz, Ohmic Contacts to Semiconductors (The Electrochemical Society, New York, 1969), pp. 3-16, 69-81.

$\therefore$ T. I. Barry and F. S. Stone, Proc. Roy. Soc. A. 255, 127 (1960).

3 J. D. Maines and E. G. S. Paige, J. Phys. C. 2, 175 (1969).

${ }^{4} \mathrm{H}$. M. Janus (to be published).

\section{Determination of a Crystal's Surface Orientation Using an X-Ray Diffractometer and a Laser}

\author{
R. L. Mozzi AND D. W. Hown \\ Raytheon Research Division, Waltham, Massachusetts 02154
}

(Received 8 January 1970; and in final form, 25 February 1970)

$T$ HE orientation of a flat surface on a crystal relative to a set of crystallographic $(h k l)$ planes is usually determined by the $\mathrm{x}$-ray Laue back reflection technique., ${ }^{1,2}$ This method requires setting the flat surface perpendicular to the x-ray beam at a known distance from the film, taking the photograph, and measuring the deviation of the $(h k l)$ spot from the pinhole in the film through which the incident $\mathrm{x}$-ray beam passes. Accuracies of $\frac{1}{2}^{\circ}$ or better are difficult to achieve this way, particularly for small flats. We describe a simple technique by which accuracies of $0.1^{\circ}$ are readily obtained and which is potentially accurate to at least $0.05^{\circ}$. The method only requires that the surface be flat and smooth enough to produce a specular reflection of an incident light beam.

The measurement is made on an $x$-ray diffractometer, such as the General Electric XRD-5, equipped with a single crystal goniostat. The arrangement, which is thoroughly described elsewhere, ${ }^{3}$ is shown schematically in Fig. 1 where the incident and reflected beams lie in a horizontal plane and the $\theta$ rotation axis is vertical. All

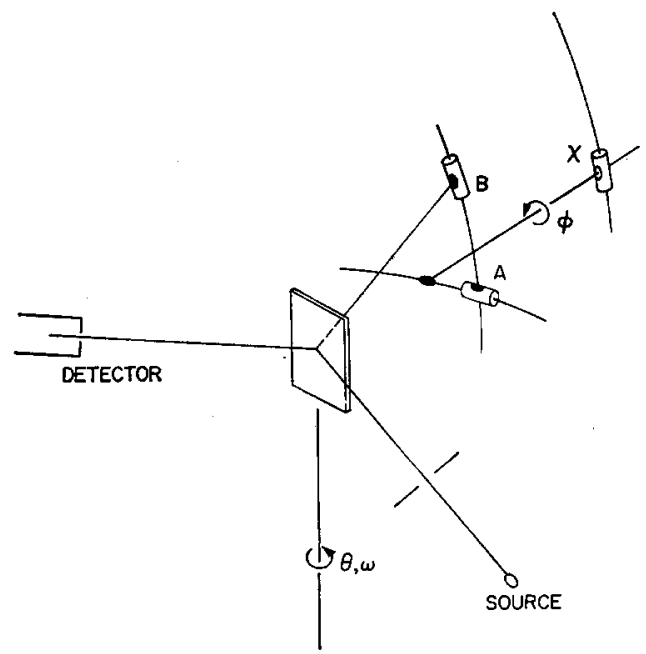

FIG. 1. Schematic diagram of a single crystal goniostat mounted on an $\mathrm{x}$-ray diffractometer. Arc movements are represented by hollow tubes constrained to move along their lengths. 